\title{
HOW CAN WE UNTAP THE ENERGY SAVING POTENTIAL OF HOUSEHOLDS? INSIGHTS FROM HOUSEHOLD PREFERENCES FOR ALTERNATIVE MEASURES
}

\author{
Azucena Gracia*ab, Luis Pérez y Pérez ${ }^{* a b}, \underline{J e s u ́ s ~ B a r r e i r o ~ H u r l e ́ ~}^{* c}$ \\ a Unidad de Economía Agroalimentaria y de los Recursos Naturales, Centro de Investigación y Tecnología \\ Agroalimentaria de Aragón (CITA). Avda. Montañana 930, 50059, Zaragoza. (agracia@cita-aragon.es, \\ lperez@aragon.es). \\ ${ }^{\mathrm{b}}$ Instituto Agroalimentario de Aragón - IA2 (CITA Universidad de Zaragoza), Zaragoza, España. \\ ${ }^{\mathrm{c}}$ European Commission. Joint Research Centre (JRC). Sevilla. (jesus.barreiro-hurle@ec.europa.eu).
}

\begin{abstract}
Reducing energy consumption is one of the steps needed to achieve a climate neutral energy system by 2050. Households account for $17.1 \%$ of final energy consumption in Spain and have a high reduction potential. However, this is difficult to achieve as it relies on the individual behaviour of millions of households. This paper tries to investigate how this behaviour could be triggered by analysing individuals' preferences for households' energy saving measures. We surveyed 401 individuals in Aragón in 2020 using an on line platform evaluating different energy saving measures applying the Best Worst Method and estimating a Latent Class Model. The results show that individuals value investments in energy saving measures, such as insulation of their home or using energy efficient appliances as the most important measures. On the contrary, daily behaviours as setting thermostats to recommended levels, turning lights and devices off, replacing traditional light bulbs with LED, using fully loaded washing appliances and setting temperature of refrigerators and freezers at ECO levels were less valued. We identified three different classes of energy saving behaviour patterns: "high potential energy savers", "convenience seekers" and "financially constrained". Our results can help policy makers when designing energy saving policies.
\end{abstract}

Keywords: household economics, economic behaviour, energy saving; best worst scaling; latent class modelling.

\section{Introduction and objectives}

As part of its pathway towards the long-term goal of achieving climate neutrality by 2050 , the EU has committed to reduce greenhouse gas emissions by at least $55 \%$ by 2030 , compared to 1990 levels. To achieve this goal, the EU will have to increase the share of renewable energy mix and to reduce overall consumption via energy efficiency and savings. In this respect, the household sector plays a crucial role, given that it is responsible for $17.1 \%$ of Spanish final energy consumption. Two main areas of energy consumption can be distinguished in households, that related to heating, lighting or the use of appliances and that related to transport by any means. For the former, household energy savings could be achieved by improving energy efficiency (e.g. switching to more energy efficient appliances) or encouraging behavioural changes in energy use (e.g. turning off devices when not in use) (Hille, 2016). While some actions increasing energy efficiency can be complex to implement and require non-negligible investments, everybody can make small adjustments to daily habits that reduce energy consumption. However, even these small changes in daily practices could be perceived as sacrifices that reduce comfort and provide only small financial savings. The paper investigates households' preferences for different energy saving measures related to both energy efficiency and behavioural changes.

\section{Methodology}

We use a stated preference approach to investigate household preferences for alternative energy saving measures. Data was obtained from an online survey carried out by a market research firm in February 2020 for a representative sample of 401 households in Aragon (north-eastern Spain). In order to determine the energy saving measures to be considered in the study, a literature review on household energy efficiency was conducted. Two types of behaviours were identified: first investments in energy efficient devices and home insulation (replacement of windows and doors, installation of more energy efficient appliances or maintaining the temperature in the home at the recommended levels in winter and summer) and second, energy saving measures in everyday life (turning off lights and electrical and electronic devices when not in use, replacing traditional light bulbs with more efficient LEDs, using washer appliances full and in ECO program or temperature regulation in refrigerators and freezers).

The analysis of household preferences for these measures was done through the Best Worst Method (BWM) (Finn and Louviere, 1992). Our objective with BWM is to obtain the relative importance that individuals assign to these measures. To do this, respondents are asked to choose the best and the worst of the measures 
in a series of questions that contain a combination of measures. Seven questions were posed, each one containing three measures and each measure appearing in three of the seven questions. For each question, respondents choose a pair of measures that maximises the difference in utility between the proposed measures (Loureiro and Dominguez-Arcos, 2012). Therefore, the probability that an individual will choose a specific pair of measures as best and worst is the probability that the utility difference between them is the greatest among all other possible utility differences of the combinations available in the set, and this probability can be assumed to take the form of some discrete choice specifications.

As one of the aims of the study is to understand the heterogeneity of individuals, we allow the parameters of the model to vary across individuals. Of the two alternatives to consider heterogeneity (Random Parameter Logit model (RPL) and latent class modelling (LCM)), the latter was selected because we assume that preferences are not unique for each individual, but are different for a given number of classes of individuals. Thus, individuals' preferences are homogeneous within each class, but vary across classes. The BWM \& LCM have been estimated using NLOGIT 6.0.

The optimal number of classes has to be determined by taking into account different statistical criteria. We considered six information criteria presented in table 1 (Hu et al., 2004). To profile the different household classes, we carried out a bivariate analysis of the respondents socio-demographic characteristics.

\section{Results}

The characteristics of the sample are close to those of the Aragonese and Spanish populations, implying that results can be extrapolated to the Aragonese population and considered similar to those of the Spanish one. The first step in our analysis is to identify the optimal number of classes that best capture heterogeneity in our sample (Table 1). These results show that the LL, the AIC, the AIC3, and the BIC decreased sharply in the three class model and then stabilize when moving to a four class model. According to these criteria, the three class model was only marginally inferior to the four-class model. On the other hand, the $\bar{\rho}^{2}$ increased up to the three classes specification and to a lesser extent when considering four classes. The high value of the Negentropy statistic reached with the three-class model, also shows an important separation between classes. While the best fit is obtained for a four-class model, the distinction between classes did not provide additional insights regarding the profiles when compared to the three-class model, therefore we focus our analysis on this model.

Table 1. Statistical indicators to determine the optimal number of individuals' classes

\begin{tabular}{|c|c|c|c|c|c|c|c|}
\hline Classes & Parameters (P) & LL & $\mathrm{AIC}^{2}$ & $\mathrm{AIC}^{3}$ & $\mathrm{BIC}^{4}$ & $\bar{\rho}^{25}$ & $\begin{array}{c}\text { Negentropy } \\
\text { Statistic }\end{array}$ \\
\hline 1 & 6 & $4,851.58$ & $9,715.17$ & $9,721.17$ & $4,859.39$ & 0.031 & - \\
2 & 12 & $4,728.74$ & $9,481.47$ & $9,493.47$ & $4,744.36$ & 0.054 & 0.62 \\
3 & 18 & $4,663.91$ & $9,363.82$ & $9,381.82$ & $4,687.34$ & 0.066 & 0.69 \\
4 & 24 & $4,608.01$ & $9,264.03$ & $9,288.03$ & $4,639.25$ & 0.076 & 0.72 \\
\hline
\end{tabular}

Notes: ${ }^{1}$ Log-likelihood at convergence; ${ }^{2}$ Akaike information criterion; ${ }^{3}$ Bozdogan Akaike information criterion;

${ }^{4}$ Bayesian information criterion; ${ }^{5}$ Akaike likelihood ratio index.

Table 2 reports the values of the estimated parameters. Taking all the individuals as a whole (the one segment model), all estimated parameters were positive and statistically different from zero at the $1 \%$ significance level. These results suggest that all energy saving measures considered were positively rated by respondents compared to the regulation refrigerators and freezers which is established as the benchmark energy saving measure as it was the least valued one, but with varying intensity. The measures most valued by respondents were those that entailed a significant economic expenditure for their implementation, such as windows \& doors, energy efficient appliances and temperature at home. The next group of measures was related to electricity use behaviour in the household, such as turning off devices, followed by replacing light bulbs and washer appliances, which were less preferred by respondents. All those measures had very different estimated parameters, meaning that individuals expressed different preferences for them. The parameter estimates for the three classes corroborated the heterogeneity of classes, as their values vary substantially between them. 
Table 2. Estimated parameters for households' energy saving measures - LCM

\begin{tabular}{|l|c|c|c|c|}
\hline & & \multicolumn{3}{|c|}{ Latent classes } \\
\hline & $\begin{array}{c}\text { One segment } \\
\text { Model }\end{array}$ & $\begin{array}{c}\text { High potential energy } \\
\text { savers }\end{array}$ & Convenience seekers & $\begin{array}{c}\text { Financially } \\
\text { constrained }\end{array}$ \\
\hline Windows \& doors & $0.730(14.76)^{* * *}$ & $2.330(8.95)^{* * *}$ & $0.966(4.85)^{* * *}$ & $0.009(0.06)$ \\
\hline Energy efficient appliances & $0.711(14.41)^{* * *}$ & $1.050(6.09)^{* * *}$ & $1.173(5.66)^{* * *}$ & $0.470(4.28)^{* * *}$ \\
\hline Temperature at home & $0.707(14.32)^{* * *}$ & $1.512(6.66)^{* * *}$ & $0.700(3.80)^{* * *}$ & $0.425(4.88)^{* * *}$ \\
\hline Turning off devices & $0.505(10.37)^{* * *}$ & $0.927(5.41)^{* * *}$ & $-0.644(-2.62)^{* * *}$ & $0.892(7.87)^{* * *}$ \\
\hline Replacing light bulbs & $0.408(8.40)^{* * *}$ & $0.801(4.04) * * *$ & $-0.273(-1.64)$ & $0.594(5.22)^{* * *}$ \\
\hline Washer appliances & $0.384(7.90)^{* * *}$ & $0.310(2.14)^{* *}$ & $0.901(4.48)^{* * *}$ & $0.261(3.18)^{* * *}$ \\
\hline Flat (\%)* & 79.3 & 85.3 & 73.0 & 78.9 \\
\hline Dwelling ownership $(\%) *$ & 78.3 & 76.7 & 87.0 & 74.6 \\
\hline Age (average) & 46.4 & $46.0^{\mathrm{a}}$ & $49.9^{\mathrm{b}}$ & $44.8^{\mathrm{a}}$ \\
\hline Male (\%)** & 49.4 & 51.7 & 59.0 & 42.7 \\
\hline University degree $(\%) *$ & 23.4 & 33.6 & 21.0 & 18.4 \\
\hline Class size & $100 \%$ & $29.5 \%(6.12)^{* * *}$ & $24.9 \%(5.02)^{* * *}$ & $45.7 \%(8,92)^{* * * *}$ \\
\hline
\end{tabular}

$* * *, * *, *$ denote statistical significance at $1 \%, 5 \%$, and $10 \%$ levels, respectively.

Different letters ${ }^{\mathrm{a}, \mathrm{b}}$ indicate that means were statistically different among classes using the Bonferroni test.

Our first segment, to which $29.5 \%$ of the sample is allocated, is characterized by very strong preferences for all proposed measures. We consider this group as the one with the highest potential to implement energy saving measures in their home, irrespective of their long term or short term nature. The most salient characteristics of households belonging to this class is the fact that it mainly resides in flats.

The other two classes show very different preferences for energy saving measures. The second class clearly prefers options that do not imply a change in behaviour and would rather invest in measures that allow them to continue with the usual lifestyle, therefore we label them as "convenience seekers". This class represents approximately one quarter of the sample. Estimated coefficients for investment related measures are significantly higher than behavioural interventions. Moreover, they negatively value turning off devices and are indifferent to replacing light bulbs by LEDs. From a socio demographic point of view, this class is characterised by being the group of respondents most living in a detached house, with the highest average age, highest number of homeowners and with less women.

On the other hand, the third class shows reverse preferences for the two types of measures considered. This class, representing nearly half of the population, is more attracted to measures that do not require investments even if it implies changing behaviour, thus we label them as "financially constrained". This group is characterised by being the youngest group, with the highest presence of women, the lowest level of education and the lowest proportion of homeowners.

Based in our finding one could consider targeting energy saver measures to different profiles. First, behaviourally driven measures should be targeted to younger households who still rent. Campaigns to improve the energy efficiency of dwellings and appliances should be targeted to homeowners and older households. With respect to subsidies for replacing appliances and undertaking investments, these should be targeted to financially constrained households, as most probably other households would undertake the investments without the financial incentive just to keep their current lifestyle.

\section{References}

Finn, A. y Louviere, J.J. (1992). "Determining the appropriate response to evidence of public concern: the case of food safety". Journal of Public Policy \& Marketing, 11(2):12-25.

Hille, S.L. (2016). "The myth of the unscrupulous energy user's dilemma: Evidence from Switzerland". Journal of Consumer Policy, 39(3):327-347.

Hu, W., Hunnemeyer, A., Veeman, M., Adamowicz, W. y Srivastava, L. (2004). "Trading off health, environmental and genetic modification attributes in food". European Review of Agricultural Economics, 31:389-408.

Loureiro, M.L. y Domínguez-Arcos, F.D. (2012). "Applying best-worst scaling in a stated preference analysis of forest management programs". Journal of Forest Economics, 18(4):381-394. 